\title{
A FÓRMULA DA SUSTENTABILIDADE DISSOLVIDA EM DESENVOLVIMENTO PERSISTE COMO SOLUÇÃO PARA AS MAZELAS DO PLANETA?
}

\author{
DOES THE FORMULA OF DISSOLVED SUSTAINABILITY IN DEVELOPMENT REMAIN \\ AS A SOLUTION TO THE PLANET'S ILLS?
}

\author{
LA FÓRMULA DE LA SOSTENIBILIDAD DISUELTA EN DESARROLLO, ¿SIGUE SIENDO \\ SOLUCIÓN PARA LOS PROBLEMAS DEL PLANETA?
}

Ivana Leila Carvalho Fernandes ${ }^{1}$

\begin{abstract}
Resumo
A proposta de um modelo de desenvolvimento voltado para sustentabilidade global está presente na pauta das organizações internacionais desde a segunda metade do século XX, sendo apontada como a saída para os problemas que assolam a humanidade. O objetivo deste texto consiste em discutir a evolução do discurso sobre o Desenvolvimento Sustentável, enquanto saída para as crises do mundo contemporâneo. Para tanto, o estudo recorreu ao método de pesquisa bibliográfica e documental. Os resultados demonstram que, apesar da importância dada aos debates construídos pelas organizações internacionais, os países não têm se comprometido com ações que efetivamente contribuam para a sustentabilidade global. Infere-se que persiste a necessidade de rigoroso monitoramento e avaliação das práticas acordadas, no sentido de que as autoridades cumpram com as metas definidas nas agendas internacionais.
\end{abstract}

Palavras-chave: Sustentabilidade. Agendas. Mudanças globais.

\begin{abstract}
The proposal for a development model focused on global sustainability has been on the agenda of international organizations since the second half of the twentieth century, being pointed out as the way out of the problems that afflict humanity. The objective of this text is to discuss the evolution of the discourse on Sustainable Development, as an outlet for the crises of the contemporary world. Therefore, the study used the bibliographical and documentary research method. The results show that despite the importance given to the debates held by international institutions, countries have not committed themselves to actions that effectively contribute to global sustainability. It is inferred that the need for rigorous monitoring and evaluation of agreed practices persists, in order for the authorities to comply with the goals set in the international agendas.
\end{abstract}

Keywords: Sustainability. Agendas. Global changes.

\section{Resumen}

La propuesta de un modelo de desarrollo dirigido a la sostenibilidad global está presente en la agenda de las organizaciones internacionales desde la segunda mitad del siglo XX, y es vista como la salida para los problemas que afectan a la humanidad. El objetivo de este texto consiste en discutir la evolución del discurso sobre el Desarrollo Sostenible, como alternativa para las crisis del mundo contemporáneo. Para ello, el estudio utilizó el método de investigación bibliográfica y documental. Los resultados demuestran que, a pesar de la importancia dada a los debates propuestos por las organizaciones internacionales, los países no se han comprometido con acciones que efectivamente contribuyan para la sustentabilidad global. Se infiere que persiste la necesidad de riguroso control y evaluación de las prácticas acordadas, en el sentido de que las autoridades cumplan con las metas definidas en las agendas internacionales.

Palabras-clave: Sustentabilidad. Agendas. Cambios globales.

\footnotetext{
1 Doutoranda do Programa de Pós-Graduação em Desenvolvimento e Meio Ambiente - PRODEMA/UFC. E-mail: ivanaleilac@yahoo.com.br.
} 


\section{Introdução}

A problemática ambiental enfrentada pelas sociedades contemporâneas vem provocando ao longo dos anos o colapso dos recursos naturais e total desequilíbrio nas relações estabelecidas entre humanidade e natureza.

O uso excessivo dos recursos naturais orientado por uma lógica de progresso reflete o modelo de desenvolvimento adotado pelas nações do mundo após a Segunda Guerra, tendo como foco o crescimento econômico e a modernização dos espaços urbanos e rurais.

Desse modo, a dinâmica descontrolada do modelo citado obteve sucesso até as proximidades da década de 1970, com a exploração ilimitada dos recursos naturais, processos de urbanização crescentes e modernização da indústria.

Nessa perspectiva, o prejuízo causado ao meio ambiente (destruição de florestas, desgaste da camada de ozônio, efeito estufa, destruição da biodiversidade, poluição e esgotamento dos recursos hídricos, entre outros) provocou repulsas no âmbito das sociedades internacionais que resultaram em revoluções e manifestações populares intencionando a criação de ações participativas e democráticas que visassem à qualidade de vida global.

Diante disso, surgiu, na década de 1970 do século passado, o debate sobre desenvolvimento sustentável no contexto das conferências internacionais realizadas pela Organização das Nações Unidas (ONU), no sentido de problematizar os danos ambientais e sociais provocados por um modelo de desenvolvimento avesso à sustentabilidade do planeta.

Nessa perspectiva, o texto ora discutido se empenha em articular as principais questões relacionadas ao Desenvolvimento Sustentável (DS) a partir do início do século XX, com base em conceitos e ações entrelaçados ao processo de evolução das ideias de DS no mundo.

\section{A sustentabilidade como espinha dorsal do desenvolvimento sustentável}

Este tópico discorre sobre a sustentabilidade como paradigma do desenvolvimento global, tecendo conhecimentos a partir de estudos fundamentados na literatura que aborda questões relacionadas às concepções, estratégias e mudanças originadas de crises ambientais históricas que assolam a humanidade. De modo concomitante, incorpora o tema sobre a Sustentabilidade entrelaçada à questão do Desenvolvimento Sustentável (DS), a partir da trajetória histórica do debate.

Nesse sentido, o termo sustentabilidade surgiu no final do século XX, em meio a um cenário global de crises políticas, econômicas, sociais e ambientais, emergentes de um projeto de desenvolvimento orientado historicamente por uma lógica de dominação humana e 
ambiental. A construção do debate sobre o tema decorre dos resultados catastróficos da II Guerra Mundial e da forte expansão industrial nas décadas de 1950 e 1960, como consequência das percepções civilizatórias frente aos danos ocasionados ao meio ambiente e à humanidade.

De acordo com Vieira (2004), esta época representou um momento de transição econômica pela qual passava o capitalismo ${ }^{2}$, em que a questão ambiental ganhou destaque como um dos temas fundamentais da agenda política internacional.

O debate se expandiu por vias diferentes, desde a escrita de obras que apresentavam críticas a relações construídas entre humanidade e natureza - como por exemplo Primavera Silenciosa (CARSON, 1969), de Rachel Carson na década de 1960 - , bem como de novas ideias como a proposta por Sachs na década de 1970, que trouxe o termo ecodesenvolvimento, com enfoque participativo de planejamento e gestão, norteado por um conjunto de postulados éticos (atendimento de necessidades humanas fundamentais), promoção da autoconfiança das populações envolvidas e cultivo da prudência ecológica. Tal conceito surgiu na efervescência de encontros importantes sobre os rumos do desenvolvimento no cenário internacional, porém não ganhou destaque no cerne dos debates encaminhados na época (SACHS, 2007). Além de Sachs, Georgescu-Roegen (2012), economista romeno, discutiu a importância de se considerar a Termodinâmica, com base na lei de entropia, nos resultados dos processos econômicos, pois o planeta corria riscos irreversíveis se o sistema econômico não sofresse alterações. Assim como Sachs (2007), suas ideias não impetraram importância e visibilidade no cerne dos debates que vigoravam nos eventos internacionais (GEORGESCU-ROEGEN, 2012).

Nessa conjuntura, diversos encontros e conferências sobre os rumos da vida no planeta aconteciam no cenário internacional, com destaque para a Conferência das Nações Unidas sobre o Meio Ambiente, em Estocolmo na Suécia no ano de 1972, que apresentou o Ambiente Humano como objeto central de debate. A Conferência direcionou suas abordagens para o ambiente sustentável e alertou para o fato de ser a ação humana a causadora da degradação da natureza, gerando riscos para o bem-estar e para a própria sobrevivência da sociedade (MACHADO; SANTOS; SOUSA, 2006).

A Conferência fomentou o interesse das nações mundiais em debater sobre a relação homem-natureza, também em criar leis, normas, planejamentos e estratégias para promover a

\footnotetext{
${ }^{2}$ Momento de retrocesso do regime fordista, modelo até então vigente, baseado na ampliação da produtividade dos fatores de produção, através do progresso técnico e no papel regulatório do Estado e das instituições multinacionais (SHNEIDER, 2004).
} 
sustentabilidade no planeta, de modo que as discussões persistiram nas décadas seguintes em importantes convenções como a Conferência de Chosica no Peru em 1976, a Conferência de Tbisili na Georgia (ex URSS) em 1977, a ECO 92 (Conferência das Nações Unidas para o Meio Ambiente e o Desenvolvimento) no Rio de Janeiro, Brasil (CARVALHO, 2006; BACHA; SANTOS; SCHAUN, 2010).

Nesta direção, a sustentabilidade ganha forma na década de 1990; foi amplamente discutida entre os estudiosos e interessados no assunto, mas a definição do tema não foi consensual entre eles; foi utilizado de maneiras diversas, dependendo do objetivo. Todavia, prevaleceu uma preocupação comum: o futuro do planeta.

Para Leff (2015), a sustentabilidade surgiu como marca de um limite e sinal da necessidade de reorientação do processo civilizatório da humanidade, portanto do reconhecimento da função de suporte da natureza, condição e processo de produção.

Boff (2015) acrescenta que a sustentabilidade corresponde a um conjunto de processos e ações que se destinam a manter a vitalidade e a integridade da mãe terra, a preservação de seus ecossistemas com todos os elementos físicos, químicos e ecológicos, que possibilitam a existência e a reprodução da vida, o atendimento das necessidades da presente e das futuras gerações, e a continuidade, a expansão e a realização das potencialidades da civilização humana em suas várias expressões.

Nessa perspectiva, a Carta da Terra, documento escrito no ano 2000 por diversas representações da sociedade civil como declaração universal de princípios fundamentais para a construção de uma sociedade global sustentável no século XXI, chama a atenção para questões fundamentais a serem percebidas e assumidas em um compromisso humanitário com o futuro das gerações do planeta:

Devemos somar forças para gerar uma sociedade sustentável global baseada no respeito pela natureza, nos direitos humanos universais, na justiça econômica e numa cultura da paz. Para chegar a este propósito, é imperativo que nós, os povos da Terra, declaremos nossa responsabilidade uns para com os outros, com a grande comunidade da vida, e com as futuras gerações (MINISTÉRIO DO MEIO AMBIENTE, 1992, p. 1).

Assim sendo, infere-se que a sustentabilidade está originalmente atrelada a um pensamento que envolve apreensão com as ações humanas direcionadas ao meio ambiente e com o futuro da humanidade. Isso, apesar de que o movimento de construção do debate sobre o uso do termo padeceu de viés histórico na sua empregabilidade, pois foi utilizado como clichê, em situações diversas no que tange a interesses públicos e privados, como forma de cooptação e alienação social. 
Nesse contexto, a sustentabilidade ao longo dos anos se ajustou à ideia do desenvolvimento sustentável, que por vezes apresenta falácias argumentativas relacionadas à proteção ambiental e futuro da humanidade, como evidencia o próximo assunto.

\section{Agendas internacionais: grandes previsões e raros avanços}

O conceito de Desenvolvimento Sustentável (DS) foi estabelecido no ano de 1987 através da construção do Relatório Brundtland, elaborado pela Comissão Mundial para o Meio Ambiente e o Desenvolvimento (CMMAD); foi compreendido como o modelo de desenvolvimento que assegura a satisfação das necessidades do presente, sem comprometer a habilidade das futuras gerações de satisfazerem suas próprias necessidades (ANDRADE, 2004).

Para Veiga e Zatz (2008), pensar o Desenvolvimento Sustentável com preocupação pelas pessoas e o meio ambiente no presente e respeitando o futuro, significou uma verdadeira revolução no mundo das ideias, mesmo com as dificuldades no avanço de práticas voltadas para a sustentabilidade do planeta.

Mas surgiram muitas críticas de estudiosos e pesquisadores de diferentes áreas, por entenderem que a proposta do DS apresentava intencionalidade econômica implícita na sua ideia fundante. Principalmente pela relação histórica estabelecida entre o termo desenvolvimento e o propósito de crescimento econômico, compreendido como um processo de expansão quantitativa perceptível nos sistemas relativamente estáveis dos países industrializados (SINGER, 1977). Também porque não esclarece sobre as necessidades do presente e do futuro e por ter apresentado como causa principal da situação de insustentabilidade do planeta, o descontrole populacional e a miséria dos países subdesenvolvidos (BARBOSA, 2008).

O relatório da CMMAD alerta para o modelo de desenvolvimento em curso, afirmando que, em termos absolutos, há um número de famintos que jamais houve no mundo e que o número aumenta a cada ano; que o mesmo ocorre com o número de analfabetos, assim como com o dos que não dispõem de água e moradia de boa qualidade e nem de lenha e carvão para cozinhar e se aquecer. Também destaca as tendências ambientais que ameaçam a vida no planeta. Esclarece ainda que o desenvolvimento é mais do que o crescimento, no entanto precisa se aliar ao crescimento para ser sustentável (CMMAD, 1991).

Nesse sentido, Furtado (1977) destaca que o desenvolvimento compreende o crescimento econômico dentro de uma estrutura complexa, que envolve a diversidade das 
formas sociais e econômicas. E chama atenção para o termo enquanto mito, pois nessa condição envolve os aspectos ambientais do progresso econômico na contemporaneidade, ideia que se fundamentou nos resultados do relatório The Limits to Growth (Limites do Crescimento) do Clube de Roma em 1972. Nessa linha, entre as principais ideias do documento destacava-se a necessidade de se deter o desenvolvimento para uma retomada do equilíbrio ambiental (FURTADO, 1996).

Esta lógica foi incorporada ao debate sobre desenvolvimento em um contexto global, tanto na Conferência de Estocolmo (1972), como também no Relatório de Brundtland (1987), que empregaram o termo Desenvolvimento Sustentável. O relatório, intitulado Our Common Future (Nosso Futuro Comum) deu vazão à expressão Desenvolvimento Sustentável como forma de garantir as necessidades sem comprometer as gerações futuras (ANDRADE, 2004).

Nesse contexto, o Desenvolvimento Sustentável se institucionalizou na Conferência Internacional de Meio Ambiente e Desenvolvimento realizada no Brasil, na cidade do Rio de Janeiro em 1992, que apresentou uma agenda de cooperação internacional, a Agenda 21, com propostas de ações para o desenvolvimento sustentável do planeta no século XXI.

A Agenda 21 se constitui como instrumento de orientação de práticas voltadas para a redução dos desgastes ambientais. Nessa ordem, discute a importância do comprometimento de cada país, no sentido de refletir sobre questões locais e globais e de investir em estudos voltados a soluções de problemas socioambientais (DRUN; GARCIA, 2011).

Convém destacar que a Agenda 21 aprofunda questões importantes para o debate da sustentabilidade, como a produção e consumo, educação, saúde, distribuição de renda, agricultura, ética, entre outros. Todavia, suas orientações não se constituem como uma obrigação global, podendo serem aceitas ou não no contexto internacional, visto que não há indicativos de monitoramento para aqueles que desprezarem suas indicações.

Ademais, apesar do aprofundamento dos debates, um trecho da Agenda 21 propõe que "o capital produtivo e o financeiro caminhem de mãos dadas com o capital natural, o humano e o social" (BRASIL, 2004), trazendo uma conotação ambígua na finalidade de equilíbrio desta relação. Também o Relatório de Brundtland expressava uma visão confiante na capacidade reguladora do mercado, em que os interesses individuais e coletivos se encontrariam para chegar a um equilíbrio (VIEIRA, 2004).

Apesar do distanciamento ideológico no tocante à questão do desenvolvimento e da sustentabilidade, segue a ordem das preocupações dirigidas ao desenvolvimento global. De modo que a ONU reuniu os líderes mundiais em setembro do ano 2000 para discutir o desenvolvimento global, no sentido de adotar a Declaração do Milênio que apresentou 8 
Objetivos de Desenvolvimento do Milênio (ODM), fundamentais para o desenvolvimento dos países. Cada ODM comportou metas específicas, que deveriam ser atingidas até 2015, sendo estes: redução da pobreza; ensino básico universal; igualdade entre sexo e autonomia das mulheres; reduzir a mortalidade infantil; melhorar a saúde materna; combater o HIV/aids, a malária e outras doenças; garantir a sustentabilidade ambiental; estabelecer uma parceria mundial para o desenvolvimento (PNUD, 2015).

Destaca-se que os objetivos propostos pela ONU receberam muitas críticas, principalmente porque a maioria dos representantes que integraram este momento representavam os países desenvolvidos; portanto os objetivos possivelmente se distanciaram de questões peculiares da realidade dos países em desenvolvimento. Assim, não abordam questões importantes como a forte desigualdade entre as nações.

Nesse contexto, Carvalho (2006) chama a atenção para temas como paz, segurança e desarmamento, direitos humanos, democracia e governança, que não foram contemplados, bem como para um objetivo específico dirigido à produção agrícola familiar, dada a sua importância para a sustentabilidade ambiental, e no combate à pobreza e à fome.

Fukuda-Parr e Greenstein (2010) afirmam que os ODM foram sem dúvida inspirações e levaram a uma inédita mobilização das nações unidas e da comunidade internacional, de modo que a ONU considera que o mundo avançou em resultados consideráveis na redução da pobreza extrema.

No entanto, estudo realizado pelos autores supracitados conclui que não houve mudanças significativas para a maioria dos países nas metas propostas, e que muitos países regrediram, principalmente no tocante à redução da pobreza, sugerindo que os ODM não atingiram suas expectativas. Para os autores, os resultados podem ser dúbios pelo fato de serem apresentados de modo global, o que pode ocultar as realidades de países em desenvolvimento.

Assim, cabe pensar que, se a pobreza for reduzida em países como a China e a Índia, que concentram a maior população pobre de renda média, os resultados se expressariam em termos globais. Nessa lógica, não faria sentido dar ajuda aos países africanos, pois eles influenciam pouco no cumprimento da meta (CARVALHO, 2006).

Apesar das dificuldades para o alcance das metas, bem como das contradições em torno das propostas, colocar a erradicação da pobreza como prioridade para o desenvolvimento sustentável global chama a atenção para a vulnerabilidade das populações pobres no mundo todo, fazendo com que surjam diferentes propostas com vistas ao alívio da condição de pobreza. 
Todavia seguem as ações e estratégias globais de DS com foco na erradicação da pobreza, de maneira que nova agenda foi apresentada no ano de 2015, na sede das Nações Unidas em Nova York. Dessa vez, com objetivos ampliados e atendendo parte das críticas direcionadas aos objetivos do milênio. O evento chamou atenção para 17 Objetivos de Desenvolvimento Sustentável (ODS) com 169 metas a seres alcançada ao longo de 15 anos. A agenda foi denominada como "Agenda 2030".

No encontro, os chefes de Estados e de Governos presentes assumiram compromisso com a erradicação da pobreza em todas as suas formas e dimensões, reconhecendo que este é o maior desafio global e um requisito indispensável para o desenvolvimento sustentável (ONU, 2015).

Os 17 objetivos do DS apresentados foram: erradicação da pobreza; fome zero e agricultura sustentável; saúde e bem estar; educação de qualidade; igualdade de gênero; água potável e saneamento; energia limpa e acessível; trabalho decente e crescimento econômico; indústria, inovação e infraestrutura; redução das desigualdades; cidades e comunidades sustentáveis; consumo e produção responsáveis; ação contra a mudança global do clima; vida na água; vida terrestre; paz, justiça e instituições eficazes; parcerias e meios de implementação.

Diante disso, percebe-se na odisseia histórica sobre o DS, que as questões que envolvem os objetivos e metas são fundamentais e devem ser aprofundadas com vistas ao contexto das mudanças internacionais. Observa-se que o debate sobre a sustentabilidade tem perpassado as Agendas e discussões sobre o modelo de desenvolvimento a ser seguido, fomentando novas ideias, discussões e propostas com vistas a resultados que comprovem a eficiência e eficácia destas intenções.

O tema mais perseguido tem sido a pobreza que, embora lentamente, tem sofrido redução, segundo a ONU, pois há duas décadas quase metade do mundo em desenvolvimento vivia em extrema pobreza. O número de pessoas agora vivendo em extrema pobreza diminuiu em mais da metade, passando de 1,9 bilhão em 1990 para 836 milhões em 2015 (ONU, 2015).

Destaca-se que, no Brasil, a situação da fome foi erradicada e a população extremamente pobre do país reduziu, de acordo com o registrado no ano de 1990, de 25,5\% para 3,5\% em 2012. Para a ONU, o país tem sido exemplo de redução da pobreza devido às políticas públicas sociais. Outro fator em que houve mudanças foi o analfabetismo na extrema pobreza; em 1990, a chance de uma família liderada por um analfabeto estar em situação de pobreza extrema era 144 vezes maior que a de uma família liderada por alguém 
com curso superior. Essa razão diminuiu em 2012 e passou a ser de apenas 11:1 (PNUD, 2015).

A FAO; IFAD; WORD FOOD PROGRAMME (2015) salienta que a redução bem sucedida da fome e da pobreza extrema nas áreas urbanas e rurais do país resultou da boa articulação entre uma série de políticas lideradas pelo governo, com forte envolvimento da sociedade civil.

Ainda assim, evidencia-se que, mesmo com as mudanças percebidas no campo da pobreza e da fome, persistem desigualdades extremas no Brasil e no mundo, tendo em vista que as mulheres continuam sendo discriminadas no acesso ao trabalho, nos bens econômicos e na participação na tomada de decisão pública e privada; crianças pertencentes a $20 \%$ das famílias mais pobres têm duas vezes mais chances de ter problemas de crescimento do que as das $20 \%$ mais ricas e são também quatro vezes mais suscetíveis de estar fora da escola (ONUBRASIL, 2015). Em países afetados por conflitos, a proporção de crianças fora da escola aumentou de 30\% em 1999 para 36\% em 2012; no contexto do meio ambiente, as emissões globais de dióxido de carbono aumentaram mais de 50\% desde 1990 e a escassez de água afeta agora $40 \%$ das pessoas no mundo, e a estimativa é que esta proporção aumente (ONUBRASIL, 2015).

Diante disso, há que se considerar a proximidade prática entre a questão da sustentabilidade e do desenvolvimento sustentável, tanto pela questão do respeito ao direito da qualidade de vida das pessoas, como pela preservação e recuperação (áreas destruídas) do meio ambiente, na intenção de garantir a sustentabilidade da presente e das futuras gerações.

\section{Considerações finais}

O desenvolvimento sustentável pode ser uma resposta às crises pelas quais passa o mundo contemporâneo, apesar das suas contradições, desde que reconheça como fundamental — para além das "necessidades das gerações" — as escolhas, capacidades e ações das pessoas no campo social, político, econômico e ambiental.

Assim sendo, persiste o interesse e esforço global na busca por estratégias para equilibrar as relações entre a humanidade e o meio ambiente, tendo como foco principal a redução da pobreza extrema e a proteção ambiental.

É notório que alguns resultados foram alcançados - ao longo dos prazos estabelecidos - a partir das metas propostas nas conferências e agendas assumidas 
internacionalmente, no entanto, ainda há muitas providências a serem encaminhadas pelas nações.

A propósito, considera-se fundamental a apresentação de propostas para a sustentabilidade com foco na garantia de ações que priorizem o meio ambiente e sua preservação. Além disso, que os acordos firmados apontem normas e regras formalizando os compromissos com cada país, de maneira que possam ser acompanhados rigorosamente a partir de monitoramento e avaliação das ações que visam o alcance de objetivos e metas estabelecidos.

Também que as autoridades públicas decidam por políticas que priorizem o alívio das condições de pobreza em todas as suas dimensões, considerando o arranjo institucional, a governança e os gastos.

\section{Referências}

ANDRADE, T. Inovação tecnológica e meio ambiente: a construção de novos enfoques. Ambientes e Sociedades, Campinas, v. 7, n. 1, p. 89-106, jan./jun. 2004.

BACHA, Maria de Lourdes; SANTOS, Jorgina; SCHAUN, Angela. Considerações teóricas sobre o conceito de sustentabilidade. In: SEGET - SIMPÓSIO DE EXCELÊNCIA EM GESTÃ̃ E TECNOLOGIA, 7., Resende, RJ, Anais [...]. Rio de janeiro: Associação Educacional Dom Bosco, 2010. Disponível em: https://www.aedb.br/seget/arquivos/artigos10/31_cons\%20teor\%20bacha.pdf. Acesso em: 7 jun. 2017.

BARBOSA, Gisele Silva. O desafio do desenvolvimento sustentável. Revista Visões, Macaé RJ, v. 1, n. 4, Edição 4, jan./jun. 2008. Disponível em: http://www.fsma.edu.br/visoes/ed04/4ed_O_Desafio_Do_Desenvolvimento_Sustentavel_Gise le.pdf. Acesso em: 4 jun. 2017.

BRASIL. Comissão de Políticas de Desenvolvimento Sustentável. Agenda 21 Brasileira: ações prioritárias. 2. ed. Brasília: Ministério do Meio Ambiente, 2004.

BOFF, Leonardo. Sustentabilidade: o que é - o que não é. Petrópolis, RJ: Vozes, 2015.

CMMAD (Comissão Mundial sobre Meio Ambiente e Desenvolvimento). Nosso futuro comum. 2. ed. Rio de Janeiro: Editora da Fundação Getúlio Vargas, 1991.

CARSON, Rachel. Primavera silenciosa. 2. ed. São Paulo: Melhoramentos, 1969.

CARVALHO, Vilson Sérgio de. Educação ambiental e desenvolvimento comunitário. 2. ed. Rio de Janeiro: Walk, 2006. 
DRUN, K.C.; GARCIA, H. M. Desenvolvimento sustentável e gestão ambiental nas organizações. Revista Cientifica Eletrônica de Ciências Ambientais Aplicadas da EDUVALE, Avaré SP, ano 4, n. 6, 2011.

FAO; IFAD; WORD FOOD PROGRAMME. The state of food insecurity in the world. Meeting the 2015 international hunger targets: taking stock of uneven progress. Rome: FAO, 2015. Disponível em: http://www.fao.org/3/a-i4646e.pdf. Acesso em: 7 mai. 2019.

FUKUDA-PARR, Sakiko; GREENSTEIN, Joshua. How should MDG implementation be measured: faster progress or meeting targets? ECONSTOR, Brasília, n. 63, Working Paper, 2010. Disponível em: https://www.econstor.eu/bitstream/10419/71808/1/637801784.pdf. Acesso em: 07 jun. 2017.

FURTADO, Celso. Teoria e política do desenvolvimento econômico. 6. ed. São Paulo: Companhia editora Nacional, 1977.

FURTADO, Celso. O mito do desenvolvimento econômico. 3. ed. São Paulo: Paz e Terra, 1996.

GEORGESCU-ROEGEN, Nicholas. O decrescimento: entropia, ecologia, economia. São Paulo: Editora Senac, 2012.

GRISER, C; SCHNEIDER, S. Políticas públicas de desenvolvimento rural no Brasil. Porto Alegre: Editora da UFRGS, 2015.

LEFF, E. Saber ambiental: sustentabilidade, racionalidade, complexidade, poder. 11. ed. Petrópolis, RJ: Vozes, 2015.

MACHADO, C. B; SANTOS, S. E; SOUZA, T. C. A sustentabilidade ambiental em questão. In: SILVA, Christian Luiz da. Desenvolvimento sustentável: um modelo analítico, integrado e adaptativo. 1. ed. Petrópolis, RJ: Vozes, 2006.

MARTINS, Sergio Roberto. Límites del desarrollo sostenible en América Latina: en el marco de las políticas de (re) ajuste económico. Pelotas: Editora UFPEL, 1995.

MINISTÉRIO DO MEIO AMBIENTE. Carta da terra. 1992. Disponível em: http://www.mma.gov.br/estruturas/agenda21/_arquivos/carta_terra.pdf. Acesso em: 24 mai. 2017.

ONU. Transformando nosso mundo: a agenda 2030 para o desenvolvimento sustentável. 2015. Disponível em: https://nacoesunidas.org/pos2015/agenda2030/. Acesso em: 7 jun. 2017.

ONU-BRASIL Novo relatório da ONU avalia implementação mundial dos Objetivos de Desenvolvimento do Milênio (ODM). 2015. Disponível em: https://nacoesunidas.org/novorelatorio-da-onu-avalia-implementacao-mundial-dos-objetivos-de-desenvolvimento-domilenio-odm/. Acesso em: 5 jun. 2017. 
PNUD. Redução da pobreza. 2014. Disponível em:

http://www.br.undp.org/content/brazil/pt/home/post-2015/sdg-overview1/mdg1.html. Acesso em: 3 jun. 2017.

PNUD. Os 8 Objetivos do Milênio (ODM). 2015. Disponível em:

http://www.br.undp.org/content/brazil/pt/home/post-2015.html. Acesso em: 5 jun. 2017.

SACHS, Ignacy. Rumo à ecossocioeconomia: teoria e prática do desenvolvimento. São Paulo: Cortez, 2007.

SHNEIDER, Sérgio. A abordagem territorial do desenvolvimento rural e suas articulações externas. Sociologias, Porto Alegre, n. 11, p. 88-125, jun. 2004. DOI: https://doi.org/10.1590/S1517-45222004000100006.

SINGER, Paul. Conceituação de desenvolvimento. In: SINGER, Paul. Desenvolvimento e crise. 2. ed. Rio de Janeiro: Paz e Terra, 1977.

VEIGA, José Eli da; ZATZ, Lia. Desenvolvimento sustentável, que bicho é esse? Campinas, SP: Autores Associados, 2008.

VIEIRA, Flavio Lúcio R.. Desenvolvimento sustentável: a história de um conceito. Saeculum - Revista de História, João Pessoa PB, n. 10, 2004. 